Article

\title{
Estimation of Surface Soil Moisture from Thermal Infrared Remote Sensing Using an Improved Trapezoid Method
}

\author{
Yuting Yang ${ }^{1,2, *}$, Huade Guan ${ }^{1,3}$, Di Long ${ }^{4}$, Bing Liu ${ }^{5}$, Guanghua Qin ${ }^{6}$, Jun Qin ${ }^{7}$ \\ and Okke Batelaan ${ }^{1,3}$
}

1 School of the Environment, Flinders University, Adelaide, SA 5042, Australia; E-Mails: huade.guan@flinders.edu.au (H.G.); okke.batelaan@flinders.edu.au (O.B.)

2 CSIRO Land and Water, Canberra, ACT 2601, Australia

3 National Centre for Groundwater Research and Training, Adelaide, SA 5042, Australia

4 State Key Laboratory of Hydroscience and Engineering, Department of Hydraulic Engineering, Tsinghua University, Beijing 100084, China; E-Mail: dlong@tsinghua.edu.cn

5 Linze Inland River Basin Research Station, Laboratory of Heihe River Eco-Hydrology and Basin Science, Cold and Arid Regions Environmental and Engineering Research Institute, Chinese Academy of Sciences, Lanzhou 730000, China; E-Mail: liubing@1zb.ac.cn

6 State Key Laboratory of Hydraulics and Mountain River Engineering, Chengdu 610065, China; E-Mail: ghqin2000@163.com

7 Laboratory of Tibetan Environment Changes and Land Surface Processes, Institute of Tibetan Plateau Research, Chinese Academy of Science, P.O. Box 2871, Beijing 100085, China; E-Mail: shuairenqin@gmail.com

* Author to whom correspondence should be addressed; E-Mail: yuting.yang@csiro.au; Tel.: +61-2-6218-3448.

Academic Editors: Nicolas Baghdadi and Prasad S. Thenkabail

Received: 15 April 2015 / Accepted: 12 June 2015 / Published: 24 June 2015

\begin{abstract}
Surface soil moisture (SM) plays a fundamental role in energy and water partitioning in the soil-plant-atmosphere continuum. A reliable and operational algorithm is much needed to retrieve regional surface SM at high spatial and temporal resolutions. Here, we provide an operational framework of estimating surface SM at fine spatial resolutions (using visible/thermal infrared images and concurrent meteorological data) based on a trapezoidal space defined by remotely sensed vegetation cover $\left(F_{\mathrm{c}}\right)$ and land surface temperature (LST). Theoretical solutions of the wet and dry edges were derived to achieve a more accurate and effective determination of the $F_{\mathrm{c}} / \mathrm{LST}$ space. Subjectivity and
\end{abstract}


uncertainty arising from visual examination of extreme boundaries can consequently be largely reduced. In addition, theoretical derivation of the extreme boundaries allows a per-pixel determination of the VI/LST space such that the assumption of uniform atmospheric forcing over the entire domain is no longer required. The developed approach was tested at the Tibetan Plateau Soil Moisture/Temperature Monitoring Network (SMTMN) site in central Tibet, China, from August 2010 to August 2011 using Moderate Resolution Imaging Spectroradiometer (MODIS) Terra images. Results indicate that the developed trapezoid model reproduced the spatial and temporal patterns of observed surface SM reasonably well, with showing a root-mean-square error of $0.06 \mathrm{~m}^{3} \cdot \mathrm{m}^{-3}$ at the site level and $0.03 \mathrm{~m}^{3} \cdot \mathrm{m}^{-3}$ at the regional scale. In addition, a case study on 2 September 2010 highlighted the importance of the theoretically calculated wet and dry edges, as they can effectively obviate subjectivity and uncertainties in determining the $F_{\mathrm{c}} /$ LST space arising from visual interpretation of satellite images. Compared with Land Surface Models (LSMs) in Global Land Data Assimilation System-1, the remote sensing-based trapezoid approach gave generally better surface SM estimates, whereas the LSMs showed systematic underestimation. Sensitivity analyses suggested that the trapezoid method is most sensitive to field capacity and temperature but less sensitive to other meteorological observations and parameters.

Keywords: surface soil moisture; trapezoid method; thermal infrared remote sensing; MODIS; Tibet Plateau

\section{Introduction}

Surface soil moisture (SM) plays an essential role in determining various land surface processes and the feedback between the Earth and the climate system [1]. However, long-term and large scale in situ SM data are limited due to logistic and economic reasons. In addition, local-scale variations in soil properties, terrain, and vegetation cover result in a high spatial variability in surface SM, which makes it difficult to fully assess regional surface soil water conditions based on limited point measurements [2].

Remote sensing techniques provide a unique opportunity to capture land surface information over large geographic extents. Particularly, microwave remote sensing is often considered most effective in characterizing near surface SM from the space (e.g., [3-5]). It has been shown that the relationship between the L-band (frequency $f=1-2 \mathrm{GHz}$, wavelength $\lambda=30-15 \mathrm{~cm}$ ) brightness temperature and the SM profile (up to $5 \mathrm{~cm}$ ) is generally stronger than that at higher frequency [5]. In addition, relatively longer wavelengths of microwave allow it to penetrate non-perceptible clouds and thus can furthest reduce the risk of losing data due to unfavorable climate conditions. On the other hand, lower frequencies (or longer wavelengths) result in coarser resolutions. For example, the Soil Moisture and Ocean Salinity (SMOS) satellite launched in November 2009 carries the low frequency L-band sensor, which provides surface SM retrievals every three days at $40 \mathrm{~km}$ resolution [6]. The Advanced Microwave Scanning Radiometer-Earth Observation System (AMSR-E) on board the Aqua satellite provides a nearly daily global coverage but with a mean spatial resolution of $\sim 56 \mathrm{~km}$ [7]. Those coarse resolution microwave products offer valuable mean SM information over large areas, but lose detailed SM spatial variability 
because the signals are smoothed out at a coarser level. Moreover, numerous studies have shown that the microwave-based method may fail over surfaces with moderate to dense vegetation (e.g., [8]).

Although it is imperative to develop disaggregation methods to downscale microwave remote sensing SM estimates into finer resolutions [9], it is worthwhile to explore approaches to estimate SM moisture directly based on other types of remotely sensed information, i.e., visible/thermal infrared remote sensing images [10]. Because the surface radiant temperature depends on surface soil water content and the distribution of vegetation, there should be a way for diagnosing SM by exploiting observations of land surface temperature (LST) in the thermal infrared band (8 to 13 microns) in combination with observations of surface greenness from the visible $(380-760 \mathrm{~nm})$ and near infrared spectrum (760 nm-1 micron). By interpreting the relationship between LST and the remotely sensed vegetation index (VI), a multitude of studies have shown that the envelope of data cloud (VI/LST) forms a triangle when a sufficiently large number of pixels are present with contaminated and outlier pixels being removed (see review by Carlson [11] for detail). In such a space, a higher VI value generally corresponds to a lower LST and a higher surface SM and vice versa. Furthermore, isolines of surface soil wetness were found in the VI/LST space [11], representing the same soil moisture availability. Once the boundaries of the triangle are defined, slopes of each soil wetness isoline can be determined by interpolation between the two boundaries that correspond to extreme dry and wet conditions, respectively [12-14]. This so-called "triangle method" has been used extensively in estimating evapotranspiration (ET) (e.g., [12,15]) but is rarely applied to estimate surface SM. Whilst a few studies reported some promise in estimating surface SM based on the triangle method (e.g., [16,17]), none of them has transitioned to an operational framework.

There are, however, issues associated with the triangle method to be resolved. First, Moran et al. [18] claimed that the triangular space, in which the driest and wettest fully vegetated surfaces have the same surface temperature, does not account for the impact of water stress on canopy transpiration, and replaced the triangle with a trapezoid. In the trapezoidal space, the temperature of the extreme dry fully vegetated surface is higher than that of the wettest surface with full vegetation cover but is lower than extreme dry bare soil surface. Yang et al. [15] demonstrated that the trapezoid is more theoretically sound than using other shapes. Second, traditional approaches for determining the extreme boundaries of the triangle (or trapezoid) space are based on visual examination of the VI/LST data points (e.g., [19]), which implicitly requires that both conditions of extreme dry (lowest SM) and extreme wet points (highest SM) be present in a study scene to ensure the validity of the triangle (or trapezoid) method [11]. This is often not the case in reality. In addition, substantial subjectivity results from the observed boundaries as well, because they can differ among operators for the same study area [12]. Furthermore, visual examination of extreme boundaries would largely increase "labor work" and therefore severely reduces the operability of the method. Third, one key assumption of the triangle (or trapezoid) method is that among-pixel variation in surface energy flux is primarily controlled by that in water availability but is not affected by differences in atmospheric conditions [20]. As a result, the triangle (or trapezoid) method is applicable for areas with relatively homogeneous meteorology.

In order to address the above-mentioned issues, this study provides an operational framework of estimating surface SM based on visible and thermal infrared information from satellite images and the trapezoid method. Rather than determining the trapezoidal boundaries from visual inspection, theoretical solutions were derived to achieve a more accurate and effective determination of the VI/LST space. 
The theoretical derivation of the extreme boundaries also allows a per-pixel determination of the VI/LST space. Consequently, the assumption of uniform atmospheric forcing over the entire scene is no longer required. In addition to surface SM retrieval, this theoretically defined trapezoidal space may also benefit other applications, such as estimation of surface ET (e.g., [21]) and surface temperature (e.g., [15]). Here, we focus on SM, as the progress of SM studies is indeed far behind that of ET and temperature retrieval from visible/thermal infrared remote sensing. The developed approach will be validated with a well-designed SM observation network on the Tibet Plateau [22], and compared with SM estimates from land surface models [23]. Meanwhile, the strength of theoretical boundaries over observed boundaries will be discussed.

\section{Methodology}

\subsection{Trapezoidal VI/LST Space}

Theoretically, four critical points related to four extreme conditions define a trapezoid (Figure 1). Points A and B represent the driest surfaces without vegetation and with full vegetation coverage $\left(F_{\mathrm{c}}\right)$, respectively. As a result, points $\mathrm{A}$ and $\mathrm{B}$ constitute the warm edge of the trapezoid space. On the warm edge, the surface has the largest water stress for the entire range of $F_{\mathrm{c}}$ (from 0 to 1), and surface SM for those surfaces is assumed to be minimum (residual soil water content, $\theta_{R}$ ). Accordingly, evaporation from soil surfaces and vegetation transpiration due to nearly complete stomatal closure on the theoretical warm edge are both taken to be zero. Though in reality, this situation would not occur frequently, the theoretical warm edge does provide a prescribed boundary condition given a certain meteorological field to confine ET/SM estimates for surfaces with generic temperatures and fractional vegetation cover. On the contrary, points $\mathrm{C}$ and $\mathrm{D}$ represent fully vegetated and bare soil surface without water stress, respectively, and segment CD is referred to as the cold edge. On the cold edge, the surface SM is at its maximum value (field capacity, $\theta_{F}$ ) and ET occurs at its potential rates.

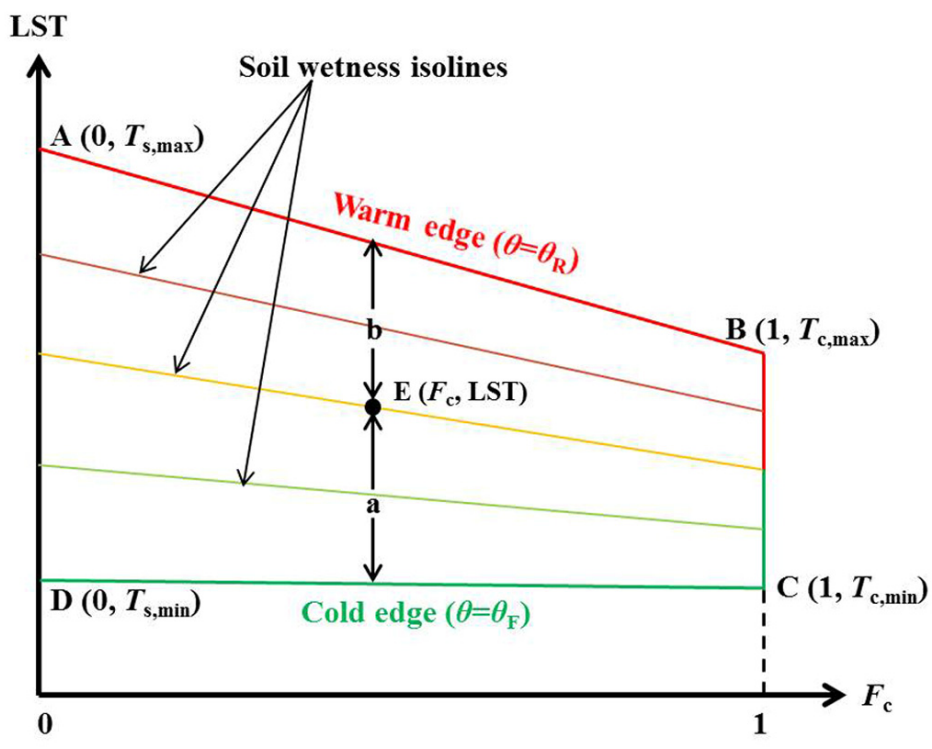

Figure 1. A sketch of the trapezoidal vegetation coverage/land surface temperature $\left(F_{\mathrm{c}} / \mathrm{LST}\right)$ space. The nomenclature is given in Section 2.1. 
Soil wetness isolines representing constant soil moisture availability were found to exist in the $F_{\mathrm{c}} / \mathrm{LST}$ space based on inverse modelling of a soil-vegetation-atmospheric transfer model [16,17] (Figure 1). The slope of each isoline is derived by interpolating the slope of the warm edge and that of the cold edge [12-14], in terms of the temperature difference between the pixel and cold edge $(a)$ and that between the pixel and warm edge $(b)$. It is noted that slopes of the soil moisture isolines in the framework used in this study range from the lowest (negative) to zero (see Section 2.2).This is because theoretically the temperature of sunlit soil should not be lower than that of vegetation along the same soil moisture isoline. As a result, surface $\operatorname{SM}(\theta$, in volumetric water content (VWC)) for each pixel can be calculated from:

$$
\begin{gathered}
\theta=\frac{b}{a+b}\left(\theta_{\mathrm{F}}-\theta_{\mathrm{R}}\right)+\theta_{\mathrm{R}} \\
a=L S T-T_{\text {min }} \\
b=\left(1-F_{\mathrm{c}}\right)\left(T_{\mathrm{s}, \max }-T_{\mathrm{c}, \text { max }}\right)+T_{\mathrm{c}, \text { max }}-L S T
\end{gathered}
$$

where $T_{\min }$ is the surface temperature for the cold edge. $T_{\mathrm{s} \text {, max }}$ and $T_{\mathrm{c}, \max }$ are surface temperatures for the driest bare soil surface and driest fully vegetated surface, respectively. Note that the term $a /(a+b)$ in Equation (1) represents surface soil moisture availability [11].

\subsection{Determination of Boundaries}

Theoretical solutions were proposed to avoid subjectivity and uncertainties in determining the trapezoidal space [12,21]. For bare soil surfaces, the radiation budget and energy budget can be described as

$$
\begin{gathered}
R_{\mathrm{n}, \mathrm{s}}=\left(1-\alpha_{\mathrm{s}}\right) S_{\mathrm{d}}+\varepsilon_{\mathrm{s}} \varepsilon_{\mathrm{a}} \sigma T_{a}^{4}-\varepsilon_{\mathrm{s}} \sigma T_{s}^{4} \\
R_{\mathrm{n}, \mathrm{s}}-G=H_{\mathrm{s}}+L E_{\mathrm{s}}=\rho C_{\mathrm{p}}\left(\frac{T_{\mathrm{s}}-T_{\mathrm{a}}}{r_{\mathrm{a}, \mathrm{a}}+r_{\mathrm{a}, \mathrm{s}}}\right)+L E_{\mathrm{s}}
\end{gathered}
$$

where $R_{n, s}$ is the net radiation for bare soil surfaces $\left(\mathrm{W} \mathrm{m}^{-2}\right) ; S_{\mathrm{d}}$ is the downward shortwave radiation $\left(\mathrm{W} \mathrm{m}^{-2}\right.$ ), which is calculated following [24]; $\alpha_{\mathrm{s}}$ is the bare surface albedo; $\sigma$ is the Stefan-Boltzmann constant $\left(5.67 \times 10^{-8} \mathrm{~W} \mathrm{~m}^{-2} \mathrm{~K}^{-4}\right)$; $\varepsilon_{\mathrm{s}}$ is the bare surface emissivity (e.g., 0.95) [25]; $\varepsilon_{\mathrm{a}}$ is the atmospheric emissivity, which is a function of air pressure $\left(P_{\mathrm{a}}\right)$ and vapor pressure $\left(e_{\mathrm{a}}\right)$ [26]. $T_{\mathrm{a}}$ is the air temperature and $T_{\mathrm{s}}$ is the bare surface temperature $(\mathrm{K}) ; G, H$ and $L E$ are ground heat flux, sensible heat flux and latent heat flux, respectively $\left(\mathrm{W} \mathrm{m}^{-2}\right) ; \rho$ is the air density $\left(\mathrm{kg} \mathrm{m}^{-3}\right) ; C_{\mathrm{p}}$ is the specific heat of air at constant pressure $\left(\mathrm{J} \mathrm{kg}^{-1} \mathrm{~K}^{-1}\right) ; r_{\mathrm{a}, \mathrm{a}}$ is the aerodynamic resistance to heat transfer between $Z_{\mathrm{om}}+d$ ( $Z_{\mathrm{om}}$ is the canopy roughness length for momentum transfer, and $d$ is the zero displacement height) and the reference height $\left(\mathrm{m} \mathrm{s}^{-1}\right) ; r_{\mathrm{a}, \mathrm{s}}$ is the aerodynamic resistance to heat flow in the boundary immediately above the soil surface $\left(\mathrm{m} \mathrm{s}^{-1}\right)$. Estimation of those aerodynamic resistance terms follows [27].

The first two terms of Taylor's formula of the upward longwave radiation $\left(\varepsilon_{\mathrm{s}} \sigma T_{\mathrm{s}}{ }^{4}\right)$ at $T_{\mathrm{a}}$ is written as [12]

$$
\varepsilon_{\mathrm{s}} \sigma T_{\mathrm{s}}^{4} \approx \varepsilon_{\mathrm{s}} \sigma T_{\mathrm{a}}^{4}+4 \varepsilon_{\mathrm{s}} \sigma T_{\mathrm{a}}^{3}\left(T_{\mathrm{s}}-T_{\mathrm{a}}\right)
$$

Substituting Equation (6) into Equation (4) and combine it with Equation (5), we can get an explicit expression of $T_{\mathrm{s}}$,

$$
T_{\mathrm{s}}=\frac{\left(1-\alpha_{\mathrm{s}}\right) S_{\mathrm{d}}+\varepsilon_{\mathrm{s}} \varepsilon_{\mathrm{a}} \sigma T_{\mathrm{a}}^{4}-\varepsilon_{\mathrm{s}} \sigma T_{\mathrm{a}}^{4}-L E_{\mathrm{s}} /\left(1-G / R_{\mathrm{n}, \mathrm{s}}\right)}{4 \varepsilon_{\mathrm{s}} \sigma T_{\mathrm{a}}^{3}+\rho C_{\mathrm{p}} /\left[\left(r_{\mathrm{a}, \mathrm{a}}+r_{\mathrm{a}, \mathrm{s}}\right)\left(1-G / R_{\mathrm{n}, \mathrm{s}}\right)\right]}+T_{\mathrm{a}}
$$


For extreme dry surfaces where there is the largest water stress, ET is completely suppressed $\left(L E_{\mathrm{s}}=0\right)$. As a result, the surface temperature for the driest bare surface (point A in Figure 1), $T_{\mathrm{s}, \max }$, is,

$$
T_{\mathrm{s}, \max }=\frac{\left(1-\alpha_{\mathrm{s}}\right) S_{\mathrm{d}}+\varepsilon_{\mathrm{s}} \varepsilon_{\mathrm{a}} \sigma T_{\mathrm{a}}^{4}-\varepsilon_{\mathrm{s}} \sigma T_{\mathrm{a}}^{4}}{4 \varepsilon_{\mathrm{s}} \sigma T_{\mathrm{a}}^{3}+\rho C_{\mathrm{p}} /\left[\left(r_{\mathrm{a}, \mathrm{a}}+r_{\mathrm{a}, \mathrm{s}}\right)\left(1-G / R_{\mathrm{n}, \mathrm{s}}\right)\right]}+T_{\mathrm{a}}
$$

where the ratio of $G / R_{\mathrm{n}, \mathrm{sis}}$ taken to be 0.35 for bare soil surfaces[28].

In a similar vein, the temperature for the driest fully vegetated surface (point B in Figure 1 ), $T_{\mathrm{c}, \max }$, can be derived as,

$$
T_{\mathrm{c}, \max }=\frac{\left(1-\alpha_{\mathrm{c}}\right) S_{\mathrm{d}}+\varepsilon_{\mathrm{c}} \varepsilon_{\mathrm{a}} \sigma T_{\mathrm{a}}^{4}-\varepsilon_{\mathrm{c}} \sigma T_{\mathrm{a}}^{4}}{4 \varepsilon_{\mathrm{c}} \sigma T_{\mathrm{a}}^{3}+\rho C_{\mathrm{p}} / r_{\mathrm{a}, \mathrm{c}}}+T_{\mathrm{a}}
$$

where $\alpha_{\mathrm{c}}$ is the albedo for fully vegetated surfaces; $\varepsilon_{\mathrm{c}}$ is the vegetation emissivity (0.98) [25]; $r_{\mathrm{a}, \mathrm{c}}$ is the aerodynamic resistance to heat transfer between canopy and the reference height $\left(\mathrm{m} \mathrm{s}^{-1}\right)$. The two albedo terms ( $\alpha_{s}$ and $\alpha_{c}$ ) in Equations (8) and (9) can be estimated either by extending the upper envelope of the $F_{\mathrm{c}} / \alpha$ space intersecting with $F_{\mathrm{c}}=0$ and $F_{\mathrm{c}}=1$, respectively, or from the look-up table for each specific type of surface provided by [29].

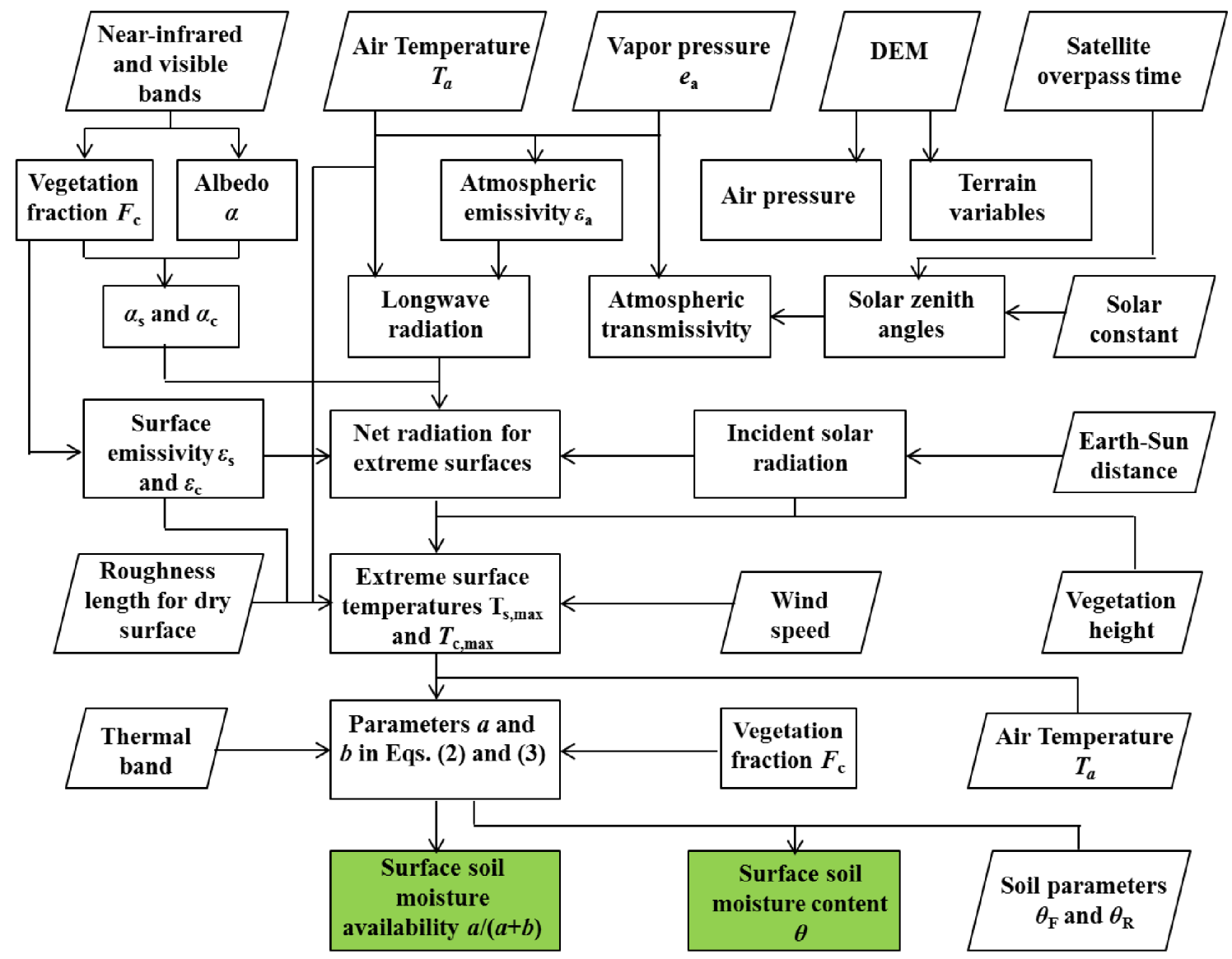

Figure 2. Flow chart of the trapezoidal model for estimating surface soil moisture (SM). Trapezoids represent input variables or parameters, and rectangles represent intermediate variables or parameters.

For the cold edge, the highest ET corresponds to the lowest sensible heat, and therefore the temperature gradient between the land surface and reference height would approach zero. As such, air temperature 
is taken as the surface temperature for the lower theoretical limiting edge (i.e., $T_{\mathrm{s}, \min }=T_{\mathrm{c}, \min }=T_{\mathrm{a}}$ ). This simplification is an operational way to determine the theoretical lower limiting edge and obviates the need for vapor pressure deficit in the work of [18]. However, this simplification may not be suited for surfaces with either extremely high vapor pressure deficit or strong advection effect [21]. A flowchart of the trapezoidal model is shown in Figure 2.

\section{Study Area and Data}

\subsection{Site Description and SM Measurement}

In situ measurements of surface SM to validate the algorithm were obtained from a well-designed soil moisture observation network located around Naqu town, Tibet $\left(31^{\circ} \mathrm{N}-32^{\circ} \mathrm{N}, 91.5^{\circ} \mathrm{E}-92.5^{\circ} \mathrm{E}\right)$, covering an area of $\sim 100 \mathrm{~km} \times 100 \mathrm{~km}$ with a mean elevation of $4650 \mathrm{~m}$ a.s.l. (the Tibetan Plateau Soil Moisture/Temperature Monitoring Network, SMTMN) (Figure 3) [22,30]. The area is fairly smooth with rolling hills despite remarkable relief in some parts. The region has a typical sub-humid monsoon climate. Annual precipitation is about $400-500 \mathrm{~mm}$, with $\sim 80 \%$ occurring during the monsoon season (June to August). The main components of soil texture are sand and silt, and exhibit a large spatial heterogeneity [31]. Organic carbon content was observed to be high within the top soil layer and declines dramatically with depth [31]. Alpine grasslands cover about $93.6 \%$ of the land surface, with a mean vegetation height of several centimeters [22]. Soil thawing and freezing are typical phenomena in the region, which generally occur around May and November, respectively [22].

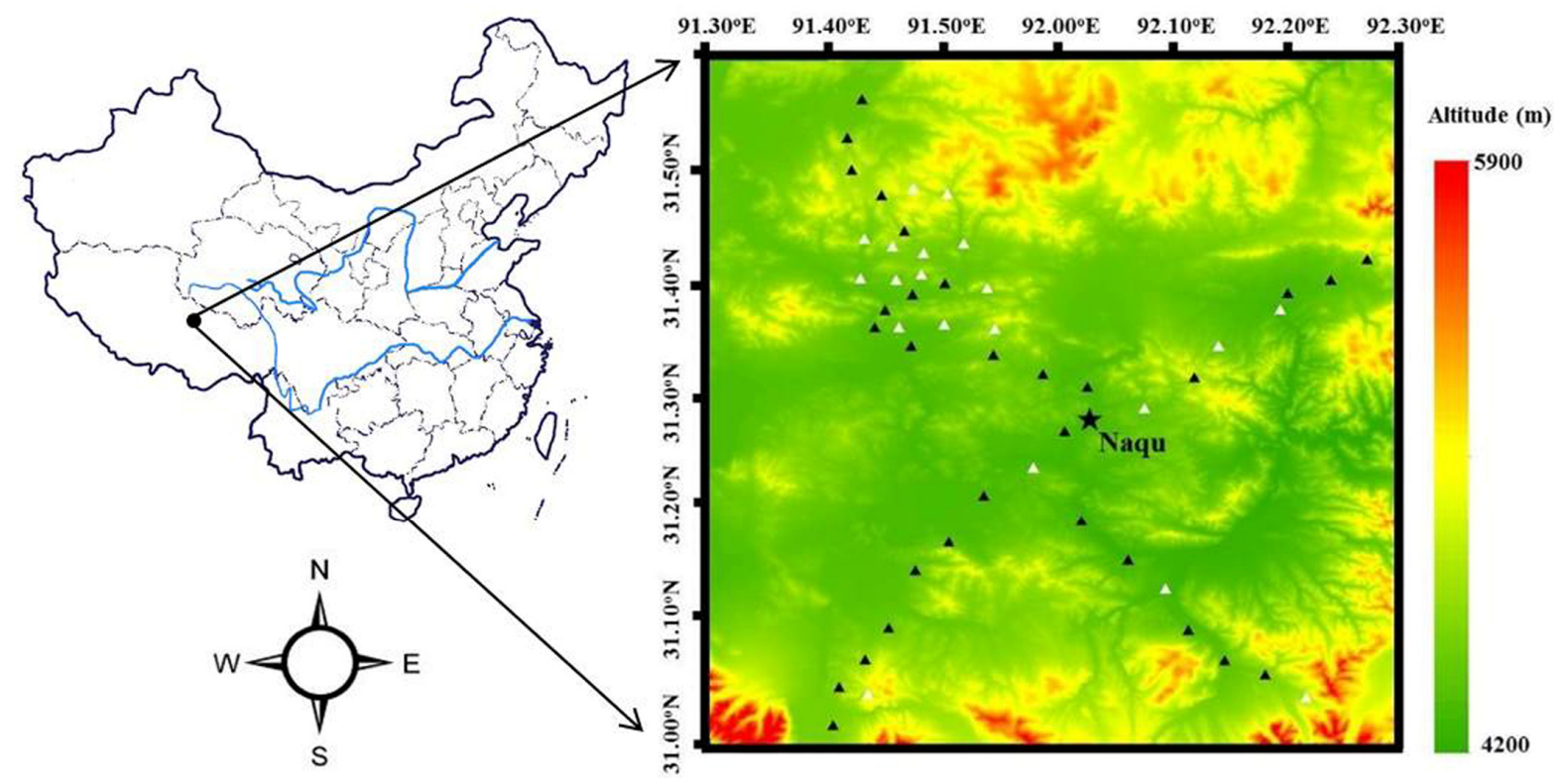

Figure 3. Location of the study area and a sketch map of the Soil Moisture/Temperature Monitoring Network (SMTMN) site distribution. The black triangles represent the first 30 sites built in 2010 and the white triangles denote the 20 sites setup in 2011 . The black pentagram shows the location of Naqu City.

Soil moisture at four depths $(0-5 \mathrm{~cm}, 10 \mathrm{~cm}, 20 \mathrm{~cm}$ and $40 \mathrm{~cm})$ were measured at 30 sites along four branches of the national/provincial roads (Figure 3) from 01/08/2010/ to 31/08/2011 with capacitance 
probes (http://www.decagon.com/) with an accuracy of $\pm 3 \% \mathrm{VMC}$ and resolution of $0.1 \% \mathrm{VMC}$. Another 20 sites were added into the measurement since July 2011. The measurement time interval was $30 \mathrm{~min}$, and each record reflected the average state of SM over the past half-hour. Sensor calibration was performed using the gravimetric method in laboratory. Detailed description of the study region and SM measurement can be found in $[22,32]$.

\subsection{Remote Sensing Data}

Moderate Resolution Imaging Spectroradiometer (MODIS) data were used in this study because of its high temporal resolution (daily) and accessible spatial resolution (250-1000 m). These data were provided by the NASA Data Center [33]. Daily LST was obtained from the global daily land surface temperature and emissivity product (MOD11A1), and broadband surface albedo was calculated based on narrowband surface reflectance from dataset MOD09GA and the algorithm proposed by [34]. The normalized difference vegetation index (NDVI) was derived from red and near-infrared bands following [35], and $F_{\mathrm{c}}$ was subsequently estimated from,

$$
F_{\mathrm{c}}=\left(\frac{\mathrm{NDVI}^{-} \mathrm{NDVI}_{\text {min }}}{\mathrm{NDVI}_{\text {max }}-\mathrm{NDVI}_{\text {min }}}\right)^{n}
$$

where NDVI $I_{\max }$ and NDVI $I_{\min }$ are NDVI for fully vegetated and bare surfaces, which are taken to be 0.85 and 0.15, respectively [36] (Donohue et al., 2013). The coefficient $n$ is a function of leaf orientation distribution within the canopy and was set a value of 2 following [37]. It should be noted that all three parameters in Equation (10) were set somehow objectively, as different studies reported different parameter values (e.g., [38]). However, the sensitivity analysis suggests that the estimated surface SM is not sensitive to variations in these parameters (see Section 4.4). All remote sensing data were re-projected into the Universal Transverse Mercator (UTM) projection and resampled to a spatial resolution of $1000 \mathrm{~m}$.

\subsection{Other Data Sources}

In addition to MODIS data, other two datasets are needed to run the algorithm. The first one is meteorological data, which was provided by the China Meteorology Data Center [39] at the Naqu station (Figure 3) to represent the regional mean climate condition (i.e., wind speed and vapor pressure). The air temperature for each pixel was corrected by considering the altitude effect based on DEM data (SRTM [40]) and a lapse rate of $-6.5^{\circ} \mathrm{C} / \mathrm{km}$. The daily meteorological measurements were downscaled to the hourly timescale based on the algorithm proposed by [41]. Then, the hourly meteorological data at satellite overpass time were used in subsequent calculation. The second dataset is soil texture, which was measured at each site. Field capacity $\left(\theta_{F}\right)$ was estimated to be the water content retained in the soil at $-0.02 \mathrm{MPa}$ of suction pressure, which is midway of most reported $\theta_{F}$ values $(-0.01 \mathrm{MPa}$ to $-0.33 \mathrm{Mpa})[42,43]$. The VG-M model was adopted to describe the soil water retention curve whose parameters were estimated from measured soil texture and organic content using the method given by [44]. The residual water content $\left(\theta_{R}\right)$ is given directly by [44]. Both meteorological and soil texture data at the site level were spatially interpolated using the Inverse Distance Weighting (IDW) method to obtain spatially-continuous inputs over the study domain. 
SM output from four land surface models (LSM), including Noah 2.7 [45], Mosaic [46], Variable Infiltration Capacity model (VIC, [47]), and Community Land Model 2.0 (CLM, [48]) with a $1^{\circ}$ spatial resolution and 3-h temporal resolution in Global Land Data Assimilation System-1 (GLDAS-1) [23] of the upper centimeters of the soil profile $(10 \mathrm{~cm}$ for Noah, $2 \mathrm{~cm}$ for Mosaic, $10 \mathrm{~cm}$ for VIC, and $4.5 \mathrm{~cm}$ for CLM) was used for comparison with the developed algorithm and ground-based measurements. Surface SM output from these LSMs of two grid cells corresponding to the study site were spatially averaged for this comparison.

\section{Results and Discussion}

The current study only considered non-frozen periods (1 August2010 31 October 2010 and 1 June 2011 31 August 2011) for model testing because: (1) only liquid water content was measured within frozen soils during winter; and (2) soil freezing and thawing processes lead to a more complex water and heat transfer dynamics within soil and between soil and the atmosphere, which may not be captured by the trapezoid framework. In addition, we estimated the theoretical VI/LST trapezoidal space for each pixel to minimize uncertainties rising from non-homogeneous atmospheric forcing over the entire study region.

\subsection{Validation with Site Observations}

As shown in Figure 4, the site-level estimates and observations agree reasonably well with each other during the entire study period, with the coefficient of determination $\left(R^{2}\right)$ of 0.73 and the root-mean-square error (RMSE) of $0.06 \mathrm{~m}^{3} \cdot \mathrm{m}^{-3}$, which falls within the AMSR-E mission accuracy requirement (i.e., the RMSE $\leq 0.06 \mathrm{~m}^{3} \cdot \mathrm{m}^{-3}$ ). However, it is noted that the trapezoid method underestimated surface $\mathrm{SM}$ at the high end, resulting in an overall underestimation of $0.02 \mathrm{~m}^{3} \cdot \mathrm{m}^{-3}$ (mean bias, defined as estimated mean minus observed mean). This may be related to the underestimation of field capacity of the surface soil layer or overestimation/underestimation of the warm/cold edge. According to the trapezoidal principle, actual soil water content is bounded by two critical values, which are the field capacity and the residual water content, respectively (Figure 1). The estimated field capacities from [44] were all lower than $0.6 \mathrm{~m}^{3} \cdot \mathrm{m}^{-3}$, whereas the observed water content reached $0.7 \mathrm{~m}^{3} \cdot \mathrm{m}^{-3}$. On the other hand, it is possible that the observed high SM reflected water content between field capacity and saturated water content, when there were rainy events shortly before the measurements or there was water ponding over the soil surface. Nevertheless, SM higher than the field capacity is not addressed in the developed method.

Another possible reason for the discrepancy is the mismatch between point-scale measurements and the $1 \mathrm{~km}$-resolution MODIS input. Although the study region is relatively flat with uniform vegetation cover, SM may still have great local variability [49]. Therefore, point observations may not be able to fully represent the average SM status within a MODIS pixel. 


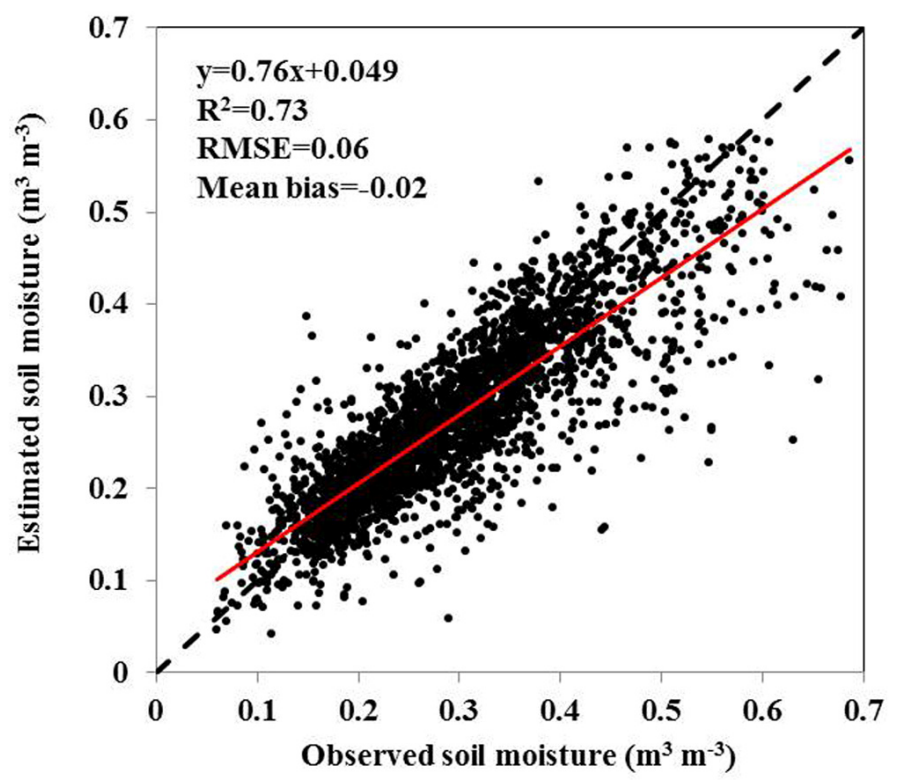

Figure 4. Comparison of estimated surface soil moisture against observed ones at each observation site.

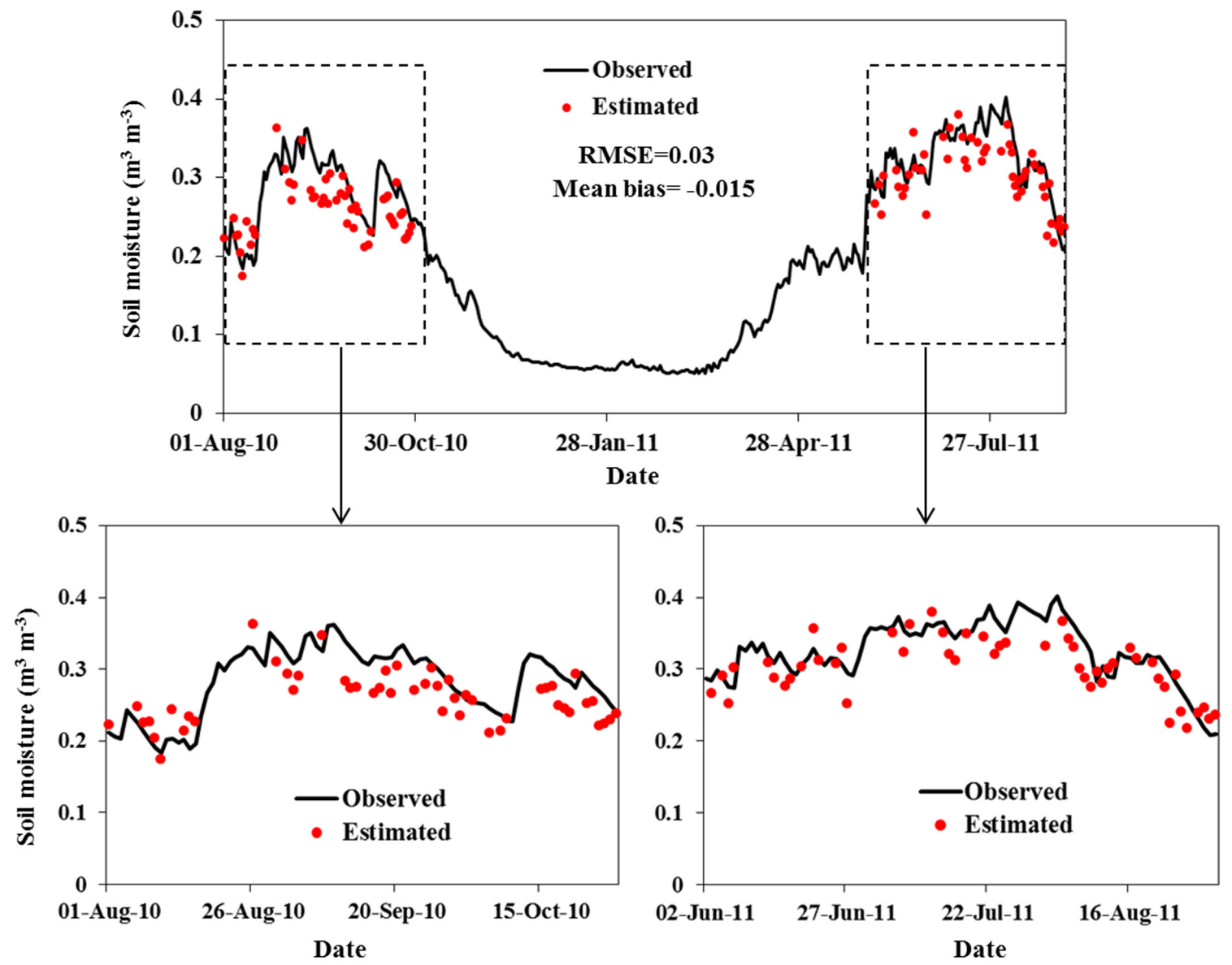

Figure 5. Comparison of daily station-averaged surface soil moisture with observed ones. Only days with MODIS data available at more than 13 sites are shown.

Comparison of estimated seasonal evolution of daily station-averaged surface SM against observations is shown in Figure 5. As MODIS images were often contaminated by clouds in the region, only days with 
available MODIS data at more than 13 sites were used for this analysis. Zhao et al. [32] suggested that averaging SM measurements from across the 13 sites can effectively reflect SM averaged with all 50 sites with an accuracy of $R \geq 0.99$ and RMSE $\leq 0.02 \mathrm{~m}^{3} \cdot \mathrm{m}^{-3}$ for the study region. Generally, the simulated SM from the trapezoidal approach captures the observations fairly well, indicating the reliability of the algorithm over a wide range of SM conditions. However, consistent with the results in Figure 4, the station-averaged estimates are generally lower than the observed ones at high soil water content.

\subsection{Spatial Distribution of Soil Moisture}

An example of the spatial distribution of estimated surface SM for 2 September 2010 is shown in Figure 6b. The MODIS images acquired on this day were generally cloud-free over the entire domain. Up-scaled regional surface SM from observed points by applying the IDW method is shown in Figure 6a. Overall, both results are in good agreement, with surface SM being lower in the southwest and middle parts and higher in the northeast parts of the region. However, a slight difference was observed for the highest SM zone. The highest SM of the trapezoidal method occurs in the northwest side of that estimated with the IDW method. This discrepancy may be attributed to a limited number of observations in the northwest area (see Figure 3), which may have significantly reduced the reliability of the IDW method in interpolating soil moisture and soil texture. On the other hand, the high SM zones in Figure 6bcorrespond to high NDVI (Figure 6c) and low LST (Figure 6d), which is a reflection of high moisture content, suggesting that the estimated SM from the trapezoidal method may be more reasonable. In addition, the estimated surface SM in the southeast part of the study site is slightly lower than the spatially interpolated one. For other days, the standard deviation of estimated surface SM agrees reasonably well with measurements (Figure 7), suggesting a good performance of the trapezoidal method in capturing the spatial variability in surface SM.
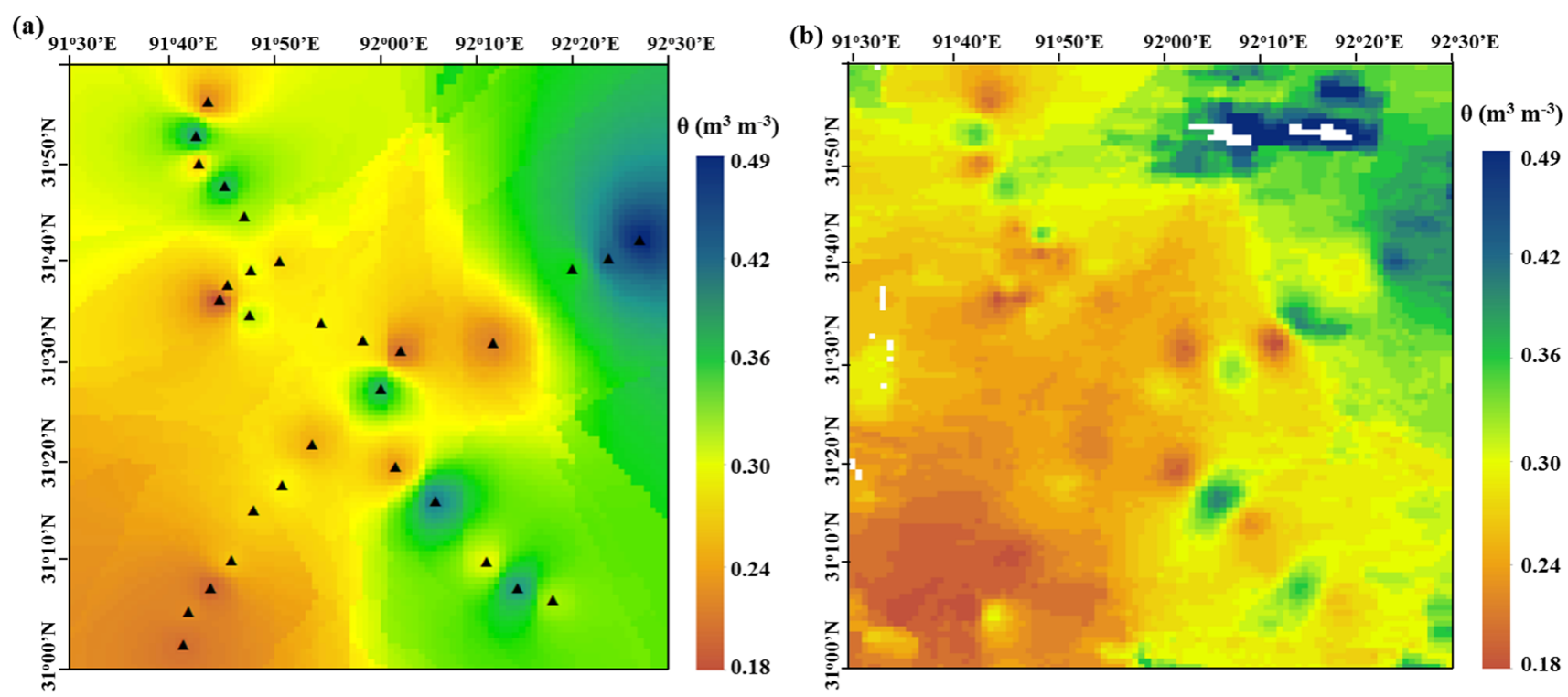

Figure 6. Cont. 
(c)

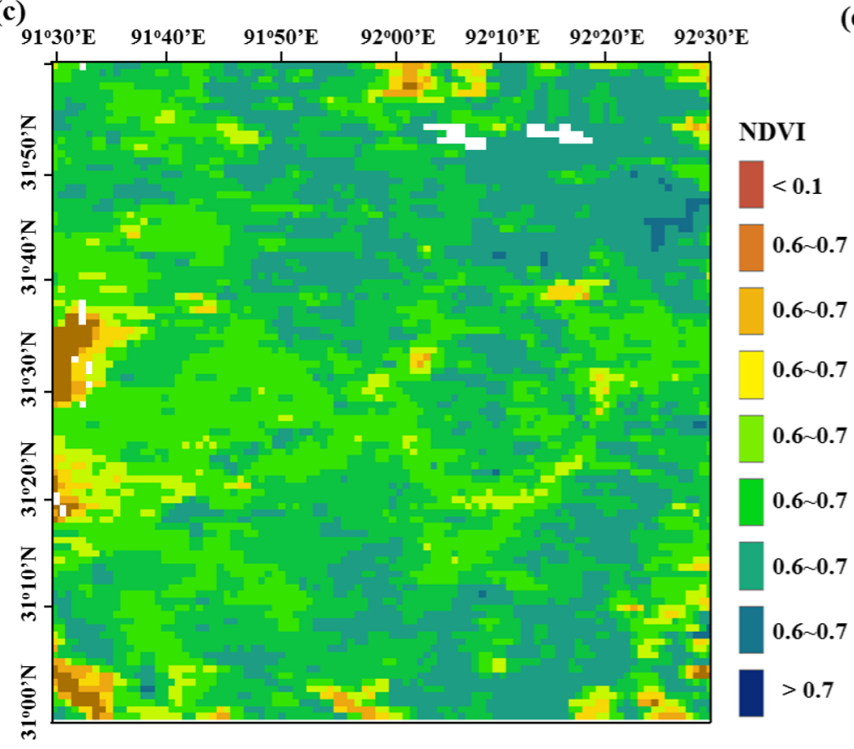

(d)

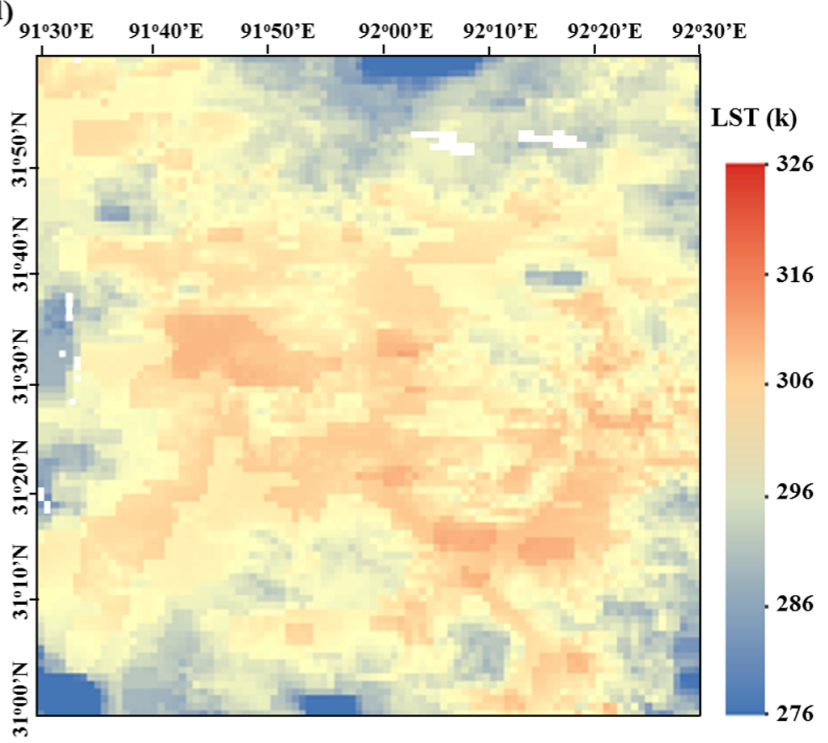

Figure 6. Spatial distribution of surface soil moisture estimated from: (a) the Inverse Distance Weighting (IDW) method; (b) the trapezoidal method for 2September 2010. The spatial patterns of concurrent normalized difference vegetation index (NDVI) and LST are shown in (c) and (d), respectively. Blank pixels in (b)-(d) indicate either water surfaces or cloudy areas.

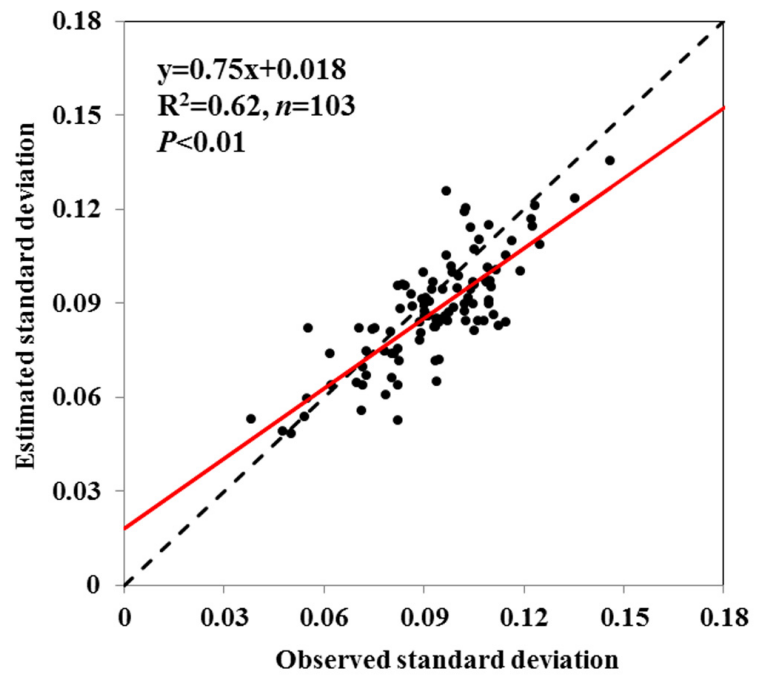

Figure 7. Comparison of standard deviation of estimated surface SM against that of observed surface SM. Each point represents the spatial variability in surface SM (standard deviation) for each day. Only days with MODIS data available at more than 13 sites are shown.

\subsection{Theoretic Boundary vs. Observed Boundary}

Accurate determination of the boundaries (warm and cold edges) of the $F_{\mathrm{c}} / \mathrm{LST}$ space is the most critical procedure of the trapezoidal method, as they jointly determine the upper and lower limits of the surface SM conditions within the domain and the relative position of each pixel in the trapezoid. However, traditional ways to determine the boundaries are based on visual examination of the images being used, which suffers from great subjectivity and uncertainties [12,13]. Simple regression of these 
boundaries based on extreme surface temperature values at each $F_{\mathrm{c}}$ interval is highly sensitive to outliers (e.g., standing water bodies, clouds, and terrain effects) and the $F_{\mathrm{c}}$ interval specified by the operator. The regressed limiting edges also depend on satellite images with varying sizes and spatial resolutions. Figure 8 shows $F_{\mathrm{c}} / \mathrm{LST}$ scatter points on 2 September 2010 over the entire study region. For the lower boundary, the observed cold edge (the lower envelope of scatter points in Figure 8) agrees well with the theoretical one (spatially averaged $T_{\mathrm{a}}$ ); whereas for the upper boundary, the observed warm edges are far below the theoretical warm edge. In addition, three different warm edges were determined by three different experienced operators based on the observed $F_{\mathrm{c}} / \mathrm{LST}$ scatterplot. Four cases of the combinations of limiting edges were set up in the trapezoidal model to estimate surface SM. Results show that the case applied with the theoretical limiting edges gives the best surface SM estimates when compared with observations, while the other three cases applied with the observed warm edge all underestimate surface SM seriously (Figure 9 and Table 1). For the study day, the observed minimum surface $\mathrm{SM}$ is $0.18 \mathrm{~m}^{3} \cdot \mathrm{m}^{-3}$, which is significantly higher than the residual water content $\left(\sim 0.05 \mathrm{~m}^{3} \cdot \mathrm{m}^{-3}\right)$, suggesting a relatively wet surface condition. Under such conditions, extremely dry surfaces do not necessarily exist in the modelling domain and the underestimation of the warm edge is likely to occur because pixels suffering from antecedent soil wetness may be considered as the dry surface pixels by the visual examination method. In addition, even though based all on images, different limiting edges determined by different operators may bring further uncertainties in the trapezoidal method, which makes model output not deterministic or ambiguous in most cases.

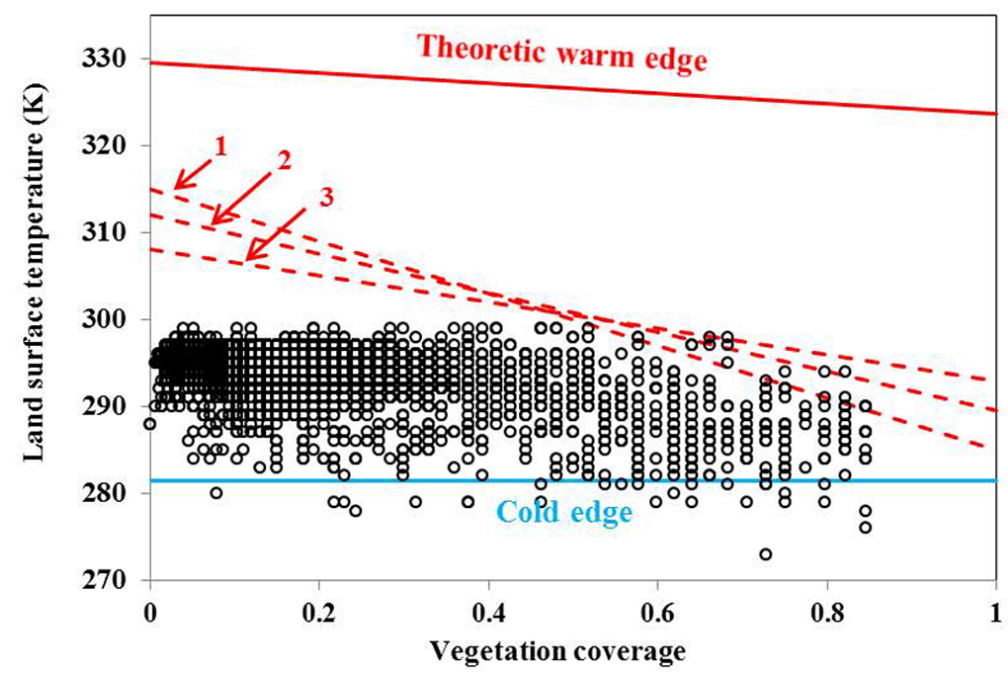

Figure 8. Scatter plot of the $F_{\mathrm{c}} / \mathrm{LST}$ space and its warm and cold edges over the entire study area for 2 September 2010. The theoretical warm and cold edges shown in the figure represent the mean positions of the warm and cold edges over all pixels. Cases 1-3 represent three warm edges determined from three different operators based on visual inspection of the VI/LST data cloud.

The study mentioned above suggests that determination of limiting edges based on visual examination/or simple regression, depending largely on subjectivity and spatial extent being studied, is far from satisfactory. The theoretical limiting edges adopted in this study effectively obviate those uncertainties, and therefore produce more reliable spatial patterns of surface SM estimates. Taking 2 September, 2010 as an example, statistics shown in Table 1 suggest that the theoretical limiting 
edges can greatly improve the accuracy of surface SM estimates compared with observed limiting edges in terms of an RMSE on an order of $\sim 0.13 \mathrm{~m}^{3} \cdot \mathrm{m}^{-3}$ and a mean bias on an order of $\sim 0.1 \mathrm{~m}^{3} \cdot \mathrm{m}^{-3}$.

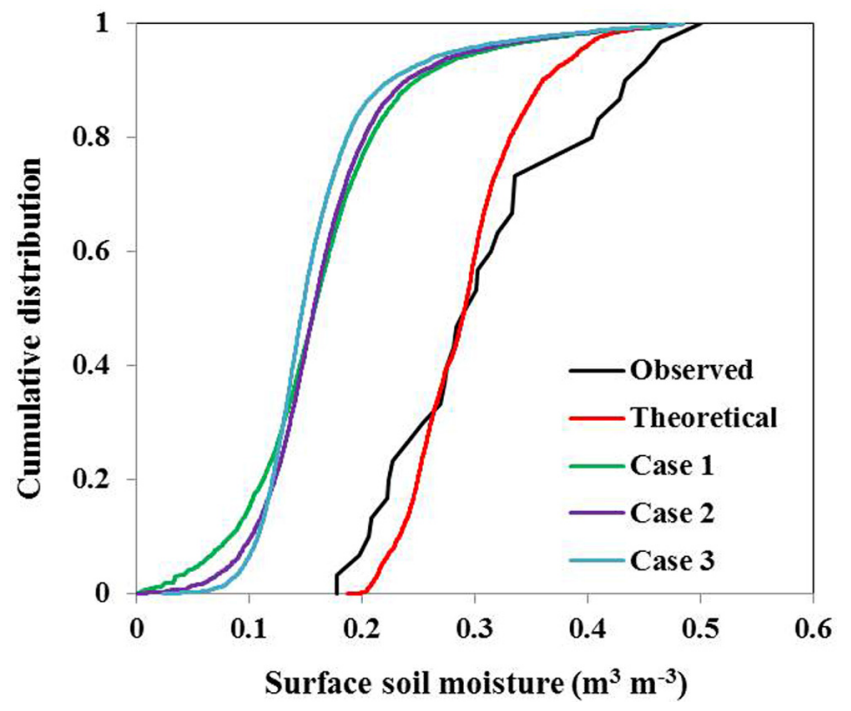

Figure 9. Cumulative distribution curves of observed surface soil moisture and those estimated from the trapezoidal method with different boundaries edges. Cases 1, 2 and 3 correspond to different warm edges shown in Figure 7.

Table 1. Statistical analysis of surface soil moisture from observations and estimated from the trapezoidal method with different boundaries edges on 2 September 2010. Cases 1, 2 and 3 correspond to different warm edges shown in Figure 7.

\begin{tabular}{ccccccc}
\hline Surface SM & Mean & Stand Deviation & CV & RMSE & Mean Bias & $\boldsymbol{R}^{\mathbf{2}}$ \\
\hline Observed & 0.31 & 0.087 & 0.28 & - & - & - \\
Theoretical & 0.29 & 0.074 & 0.26 & 0.05 & -0.02 & 0.86 \\
Case 1 & 0.17 & 0.073 & 0.43 & 0.18 & -0.14 & 0.42 \\
Case 2 & 0.17 & 0.070 & 0.41 & 0.18 & -0.14 & 0.46 \\
Case 3 & 0.16 & 0.062 & 0.39 & 0.19 & -0.15 & 0.54 \\
\hline
\end{tabular}

\subsection{Sensitivity Analysis}

A local sensitivity analysis was conducted to examine how uncertainties in trapezoidal method-estimated surface SM could be apportioned to different sources of uncertainty in model input. The sensitivity to the $i$ th forcing variable or parameter is assessed by calculating surface SM with a set of baseline parameters $\left(\mathrm{SM}_{0}\right)$ and comparing this with surface $\mathrm{SM}$ calculated by varying the $i$ th parameter $\left(\mathrm{SM}_{ \pm}\right)$; the sensitivity index is

$$
S_{\mathrm{i}}=\frac{S M_{ \pm}-S M_{\mathrm{o}}}{S M_{\mathrm{o}}} \times 100 \%
$$

The variation ranges and steps of each input variable are set as $2 \mathrm{~K}$ for temperature variables, with a step of $0.5 \mathrm{~K}$, and $20 \%$ for other variables, with a step of 5\%. Data on 2 September 2010 was used for analysis because of better data quality. 
As shown in Table 2, the surface SM estimate is most sensitive to changes in field capacity $\left(\theta_{F}\right)$. An increase of $20 \%$ in $\theta_{F}$ resulted in a $19.08 \%$ increase in estimated surface SM, and a decrease of $20 \%$ in $\theta_{F}$ resulted in a $19.02 \%$ decrease in surface SM estimates. In the current study, $\theta_{F}$ was underestimated in some regions and therefore resulted in underestimation of surface SM. However, another important hydrological variable, surface soil moisture availability $(=b /(a+b)$ or EF in Figure 1) [17] does not require information on soil hydraulic properties. Thus, even under conditions without a priori knowledge of soil parameters, surface soil moisture availability can still be reliably retrieved by the developed trapezoidal method.

Temperature plays a fundamental role in determining the shape of the trapezoidal space. The estimated surface SM showed positive correlations with $T_{\mathrm{a}}$ but is negatively correlated with LST (Table 2). An increase of $2 \mathrm{~K}$ in LST and $T_{\text {a }}$ resulted in a $6.06 \%$ decrease and $5.43 \%$ increase in estimated SM, while a $2 \mathrm{~K}$ decrease in LST and $T_{\mathrm{a}}$ could lead to a $6.06 \%$ increase and $5.22 \%$ decrease in SM estimates, respectively.

For other variables, results indicate that wind speed $(u), \alpha_{c_{-} \max }, \alpha_{s_{-} \max }$, and $e_{\mathrm{a}}$ are negatively correlated with SM estimates, while $\theta_{R}, \mathrm{NDVI}_{\max }, \mathrm{NDVI}_{\min }$ and $n$ show positive relationships with SM estimates. However, changes in none of those variables resulted in significant variability in estimated surface SM. This suggests that although there are uncertainties in determining some of those variables, e.g., $\alpha_{c_{-} \max }, \alpha_{\mathrm{s}_{-} \max }, \mathrm{NDVI}_{\max }, \mathrm{NDVI}_{\min }$ and $n$, it will not greatly affect the accuracy of surface SM estimates.

Table 2. Relative sensitivity of estimated surface soil moisture from the trapezoidal method to input variables at the SMTMN site on 2 September 2010.Numberswithin each bracket indicate variations in temperature variables (i.e., $\left.-2{ }^{\circ} \mathrm{C}-2{ }^{\circ} \mathrm{C}\right)$, and numbers outside each bracket show variations in other variables (i.e., $-20 \% \sim 20 \%$ ).

\begin{tabular}{ccccccccc}
\hline Variation (\%/K) & $-\mathbf{2 0}(-\mathbf{2})$ & $-\mathbf{1 5}(-\mathbf{1 . 5})$ & $\mathbf{- 1 0}(-\mathbf{1})$ & $\mathbf{- 5}(-\mathbf{0 . 5})$ & $\mathbf{5 ( 0 . 5 )}$ & $\mathbf{1 0}(\mathbf{1})$ & $\mathbf{1 5}(\mathbf{1 . 5})$ & $\mathbf{2 0}(\mathbf{2})$ \\
\hline $\mathrm{LST}$ & 6.06 & 4.56 & 3.03 & 1.53 & -1.50 & -3.03 & -4.56 & -6.06 \\
$\mathrm{Ta}$ & -5.22 & -3.94 & -2.65 & -1.32 & 1.36 & 2.72 & 4.08 & 5.43 \\
$u$ & 3.38 & 2.72 & 1.85 & 0.94 & -0.91 & -1.85 & -2.79 & -3.76 \\
$\alpha_{\mathrm{c} \_} \max$ & 0.49 & 0.38 & 0.24 & 0.14 & -0.10 & -0.24 & -0.35 & -0.49 \\
$\alpha_{\mathrm{s} \_} \max$ & 2.33 & 1.78 & 1.22 & 0.63 & -0.73 & -1.25 & -1.95 & -2.65 \\
$e_{\mathrm{a}}$ & 0.21 & 0.17 & 0.10 & 0.07 & -0.03 & -0.10 & -0.14 & -0.17 \\
$\theta_{\mathrm{F}}$ & -19.02 & -14.29 & -9.52 & -4.73 & 4.75 & 9.57 & 14.32 & 19.08 \\
$\theta_{\mathrm{R}}$ & -0.54 & -0.41 & -0.28 & -0.14 & 0.14 & 0.28 & 0.41 & 0.54 \\
$\mathrm{NDVI}_{\max }$ & -1.43 & -0.94 & -0.56 & -0.24 & 0.21 & 0.38 & 0.56 & 0.66 \\
$\mathrm{NDVI}_{\min }$ & -0.03 & -0.03 & 0.00 & 0.00 & 0.03 & 0.03 & 0.07 & 0.07 \\
$n$ & -0.35 & -0.24 & -0.14 & -0.07 & 0.10 & 0.17 & 0.24 & 0.31 \\
\hline
\end{tabular}

\subsection{Comparison with Land Surface Models}

Comparison of surface SM from the developed trapezoidal approach and output from four LSMs in GLDAS-1 and the one estimated with the trapezoidal method with surface SM observations are shown in Figure 10. Again, this comparison was made only on days with sufficient remote sensing data (data available at more than 13 sites). Two grid cells of the LSMs were averaged to represent the mean surface SM status over the study region $\left(\sim 1^{\circ} \times 1^{\circ}\right)$. To better match the depth at which surface SM 
were measured $(0-5 \mathrm{~cm})$, LSM-based surface SM from the CLM model was obtained by averaging the uppermost two layers $(0-4.5 \mathrm{~cm})$ and those from other three LSMs were acquired directly from the first soil layer, i.e., 0-2 cm for Mosaic, 0-10 cm for VIC, and 0-10 cm for Noah.
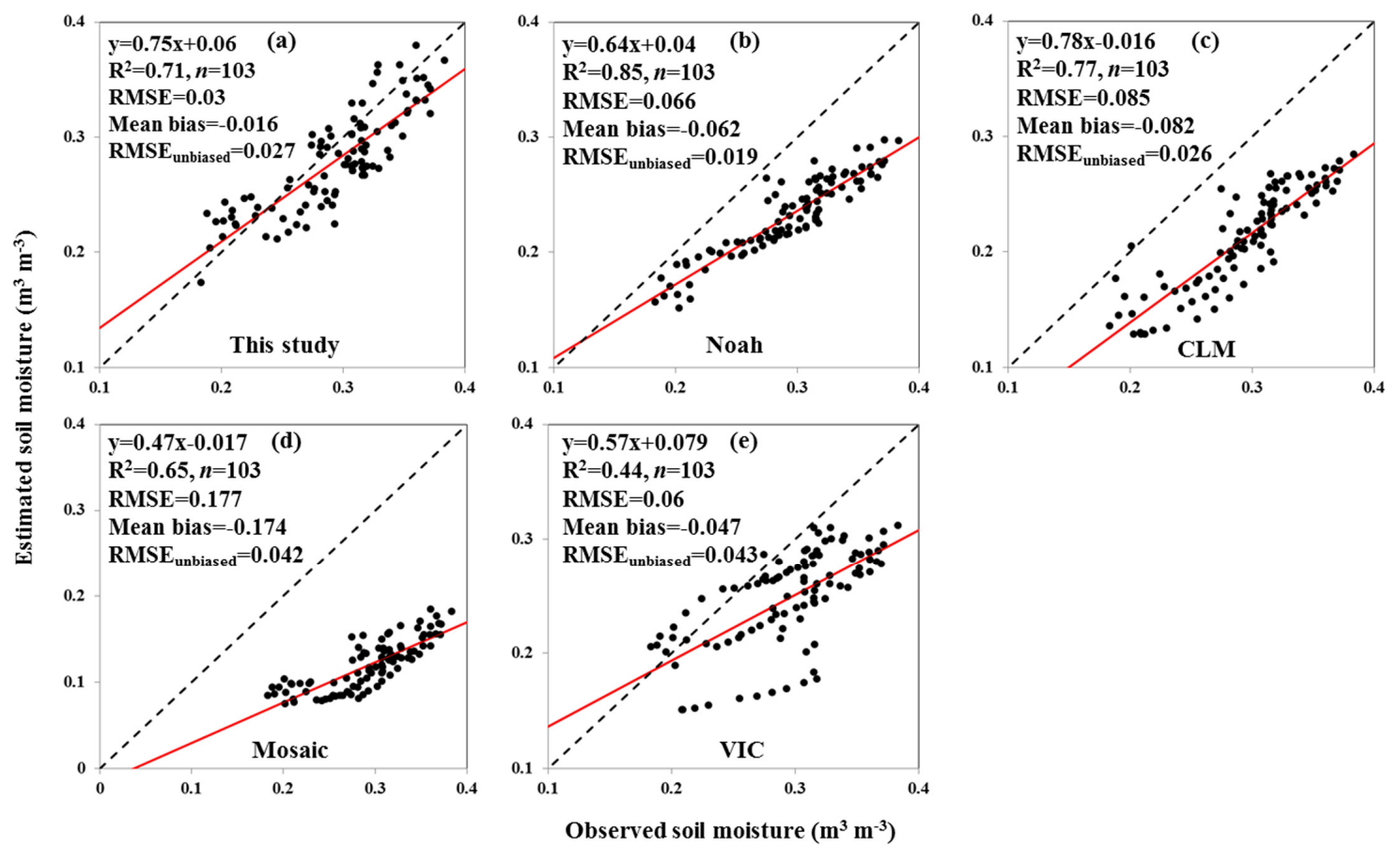

Figure 10. Comparison of daily area-averaged surface soil moisture estimated from the trapezoidal method and four land surface models against soil moisture observations. Only days with MODIS data available at more than 13 sites were shown.

Results show that all four LSMs systematically underestimated the surface SM, while the remote sensing-based trapezoidal method slightly underestimated surface SM when surface SM is high and overestimated it when surface SM is low (Figure 10). Among all methods, the trapezoidal model performed best during the study period in terms of RMSE and mean bias. With respect to temporal dynamics, Noah and CLM performed better than the trapezoidal method, as evidenced by a higher $R^{2}$

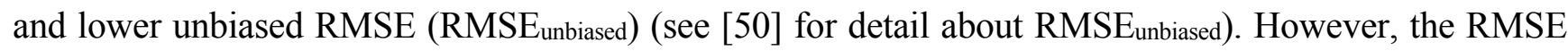
and mean bias of Noah are $\sim$ two times and four times larger than the trapezoidal method, and those of CLM are $\sim$ three times and five times larger than the trapezoidal method, respectively, suggesting a systematical underestimation of surface SM by the two models (i.e., Noah and CLM). For the four LSMs, Noah and VIC have smaller underestimation followed by CLM, and the Mosaic model shows the largest negative mean bias. Nevertheless, this may be partially ascribed to different model structures, e.g., varying surface soil layers in different LSMs, as the shallower soil layer generally dries out faster than deeper ones.

As discussed in previous studies [51-54] reliability of LSMs depends largely on accuracy of atmospheric forcing and model parameters. The more inputs for a model, the higher uncertainties may be brought. Compared with LSMs, the remote sensing-based trapezoidal method requires much fewer inputs, e.g., precipitation and soil hydraulic conductivity required in these prognostic LSMs are not involved in the diagnostic trapezoidal approach. Alternatively, LSMs provide continuous outputs 
while remote sensing-based approaches are often subjected to various types of noises, e.g., cloud contamination. Considering the advantages of both approaches, a data assimilation framework using remotely estimated surface SM is advocated to improve performance of LSMs and would consequently provide better surface SM output.

\section{Conclusions}

This study develops an algorithm to retrieve surface SM based on visible, near-infrared, and thermal infrared remotely sensed information and the trapezoidal $F_{\mathrm{c}} / \mathrm{LST}$ space. Different from other trapezoidal (or triangular) methods, theoretical solutions of the limiting edges were derived in the developed algorithm to reduce subjectivity and uncertainties in configuring the $F_{\mathrm{c}} / \mathrm{LST}$ space arising from visual interpretation of satellite images. This feature makes the trapezoidal method applicable to regions with various land cover conditions, even over highly heterogeneous surfaces. As the extreme conditions theoretically exist and the estimation of surface SM is pixel-independent, the VI/LST space and surface SM can be accurately estimated for each pixel once the spatial distribution of meteorological variables can be well defined [13].

Performance of the proposed algorithm was tested at the SMTMN site in central Tibet with MODIS data. Results showed that the trapezoidal method is able to reproduce spatial and temporal patterns of observed surface SM with an RMSE of $0.06 \mathrm{~m}^{3} \cdot \mathrm{m}^{-3}$ at the field scale and $0.03 \mathrm{~m}^{3} \cdot \mathrm{m}^{-3}$ at the regional scale, respectively. In addition, a case study on 2 September 2010 demonstrates the importance of theoretical boundaries, as the surface SM estimated with the traditionally observed boundaries is significantly underestimated, which consequently resulted in the underestimation of surface SM. Compared with LSMs, the remote sensing-based trapezoidal method gives generally better surface SM estimates, while LSMs show systematic underestimation, which may be attributed to uncertainties in model inputs and parameters over the Tibet Plateau [51]. Sensitivity analysis suggests that the trapezoidal method is most sensitive to field capacity and temperature but less sensitive to other meteorological observations and parameters.

Compared with microwave remote sensing-based SM estimates which have a mesoscale spatial resolution (e.g., $\sim 40 \mathrm{~km}$ ), our results show that there are merits of using thermal/visible satellite images to retrieve surface SM at a much finer scale due to their relatively short wavelength. On the other hand, the relatively short wavelength does not allow the sensors to penetrate through cloud covers, which makes images prone to be contaminated by clouds (particularly for humid regions where cloud covers are often thick). This would lead to non-continuous SM estimates both spatially and temporally. One solution is to combine the thermal/visible images with microwave remote sensing to make the most of both observations (i.e., finer spatial resolution for thermal infrared/visible remote sensing and spatiotemporal consistency and continuity for microwave remote sensing). This may be achieved by either using thermal infrared/visible information to downscale microwave-based SM estimates [9] or using microwave-based SM estimates to constrain SM from thermal infrared/visible information at large scales. 


\section{Acknowledgment}

The soil moisture dataset used in this study was provided by the Data Assimilation and Modelling Center for Tibetan Multi-spheres, the Institute of Tibetan Plateau Research at the Chinese Academy of Sciences. This work is financially supported by the Open Research Fund Program of the State key Laboratory of Hydroscience and Engineering (Grant No. sklhse-2014-A-01 and sklhse-2014-A-02).

\section{Author Contributions}

Yuting Yang and Huade Guan designed the study. Yuting Yang, Huade Guan, Di Long performed research and analyzed the results. All authors contributed in results discussion and manuscript writing.

\section{Conflicts of Interest}

The authors declare no conflict of interest.

\section{References}

1. Seneviratne, S.I.; Corti, T.; Davin, E.L.; Hirschi, M.; Jaeger, E.B.; Lehner, I.; Orlowsky, B.; Teuling, A.J. Investigating soil moisture-climate interactions in a changing climate: A review. Earth-Sci. Rev.2010, 99, 125-161.

2. Wood, E.F. Effects of soil moisture aggregation on surface evaporative fluxes. J. Hydrol. 1997, 190, 397-412.

3. Entekhabi, D.; Njoku, E.G.; O’Neill, P.E.; Kellogg, K.H.; Crow, W.T.; Edelstein, W.N.; Entin, J.K.; Goodman, S.D.; Jackson, T.J.; Johnson, J.; et al. The soil moisture active passive (SMAP) mission. Proc. IEEE 2010, 98, 704-716.

4. McCabe, M.F.; Gao, H.; Wood, E.F. Evaluation of AMSR-E-derived soil moisture retrievals using ground-based and PSR airborne data during SMEX02. J. Hydrometeorol. 2005, 6, 864-877.

5. Wanger, W.; Bloschi, G.; Pampaloni, P.; Calvet, J.; Bizzarri, B.; Wigneron, J.P.; Kerr, Y. Operational readiness of microwave remote sensing of soil moisture for hydrologic applications. Nord. Hydrol. 2007, 38, 1-20.

6. Kerr, Y.H.; Waldteufel, P.; Wigneron, J.P.; Martinuzzi, J.; Font, J.; Berger, M. Soil moisture retrieval from space: The soil moisture and ocean salinity (SMOS) mission. IEEE Trans.Geosci. Remote Sens. 2001, 39, 1729-1735.

7. Gruhier, C.; de Rosnay, P.; Hasenauer, S.; Holmes, T.; de Jeu, R.; Kerr, Y.; Mougin, E.; Njoku, E.; Timouk, F.; Wagner, W.; et al. Soil moisture active and passive microwave products: Intercomparison and evaluation over a sahelian site. Hydrol. Earth Syst. Sci. 2010, 14, 141-156.

8. Schmugge, T.J. Remote Sensing of Soil Moisture; Wiley: New York, NY, USA, 1985.

9. Merlin, O.; Al Bitar, A.; Walker, J.P.; Kerr, Y. An improved algorithm for disaggregating microwave-based soil moisture based on red, near-infrared and thermal infrared data. Remote Sens. Environ. 2010, 114, 2305-2316.

10. Anderson, M.C.; Norman, J.M.; Mecikalski, J.R.; Otkin, J.A.; Kustas, W.P. A climatological study of evapotranspiration and moisture stress across the continental united states based on thermal remote sensing: 1. Model formulation. J. Geophys. Res.: Atmos. 2007, 112, D10117. 
11. Carlson, T.N. An overview of the "triangle method" for estimating surface evapotranspiration and soil moisture from satellite imagery. Sensors 2007, 7, 1612-1629.

12. Long, D.; Singh, V.P.; Scanlon, B.R. Deriving theoretical boundaries to address scale dependencies of triangle models for evapotranspiration estimation. J. Geophys. Res.: Atmos. 2012, 117, D05113.

13. Yang, Y.; Shang, S. A hybrid dual-source scheme and trapezoid framework-based evapotranspiration model (HTEM) using satellite images: Algorithm and model test. J. Geophys. Res.: Atmos. 2013, $118,2284-2300$.

14. Zhang, R.H.; Sun, X.M.; Wang, X.M.; Xu, J.P.; Zhu, Z.L.; Tian, J. An operational two-layer remote sensing model to estimate surface flux in regional scale: Physical background. Sci. China Ser. D 2005, 48, 225-244.

15. Yang, Y.; Scott, R.L.; Shang, S. Modeling evapotranspiration and its partitioning over a semiarid shrub ecosystem from satellite imagery: A multiple validation. J. Appl. Remote Sens. 2013, 7, doi:10.1117/1.JRS.7.073495.

16. Carlson, T.N.; Gillies, R.R.; Perry, E.M. A method to make use of thermal infrared temperature and NDVI measurements to infer surface soil water content and fractional vegetation cover. Remote Sens. Rev. 1994, 9, 161-173.

17. Gillies, R.R.; Carlson, T.N. Thermal remote sensing of surface soil water content with partial vegetation cover for incorporation into climate models. J. Appl. Meteorol. 1995, 34, 745-756.

18. Moran, M.S.; Clarke, T.R.; Inoue, Y.; Vidal, A. Estimating crop water deficit using the relation between surface-air temperature and spectral vegetation index. Remote Sens. Environ. 1994, 49, $246-263$.

19. Choi, M.; Kustas, W.P.; Anderson, M.C.; Allen, R.G.; Li, F.; Kjaersgaard, J.H. An intercomparisonof three remote sensing-based surface energy balance algorithms over a corn and soybean production region (Iowa, U.S.) during smacex. Agric. For. Meteorol. 2009, 149, 2082-2097.

20. Stisen, S.; Sandholt, I.; Nørgaard, A.; Fensholt, R.; Jensen, K.H. Combining the triangle method with thermal inertia to estimate regional evapotranspiration-Applied to MSG-SEVIRI data in the Senegal River Basin.Remote Sens. Environ. 2008, 112, 1242-1255.

21. Yang, Y.; Long, D.; Guan, H.; Liang, W.; Simmons, C.; Batelaan, O. Comparison of three dual-sourceremote sensing evapotranspiration models during the MUSOEXE-12 campaign: Revisit of model physics. Water Resour. Res. 2015, 51, 3145-3165.

22. Yang, K.; Qin, J.; Zhao, L.; Chen, Y.; Tang, W.; Han, M.; Lazhu; Chen, Z.; Lv, N.; Ding, B.; et al. A multiscale soil moisture and freeze-thaw monitoring network on the third pole. Bull. Am. Meteorol. Soc. 2013, 94, 1907-1916.

23. Rodell, M.; Houser, P.R.; Jambor, U.; Gottschalck, J.; Mitchell, K.; Meng, C.J.; Arsenault, K.; Cosgrove, B.; Radakovich, J.; Bosilovich, M.; et al. The global land data assimilation system. Bull. Am. Meteorol. Soc. 2004, 85, 381-394.

24. Allen, R.G.; Pereira, L.S.; Raes, D.; Smith, M. Crop Evapotranspiration-Guidelines for Computing Crop Water Requirement; United Nations Food and Agriculture Organization: Rome, Italy, 1998.

25. Tasumi, M. Progress in Operational Estimation of Regional Evapotranspiration Using Satellite Imagery; University of Idaho: Moscow, ID, USA, 2003.

26. Brutsaert, W. On a derivable formula for long-wave radiation from clear skies. Water Resour. Res. 1975, 11, 742-744. 
27. Sánchez, J.M.; Kustas, W.P.; Caselles, V.; Anderson, M.C. Modelling surface energy fluxes over maize using a two-source patch model and radiometric soil and canopy temperature observations. Remote Sens. Environ. 2008, 112, 1130-1143.

28. Long, D.; Singh, V.P. A two-source trapezoid model for evapotranspiration (TTME) from satellite imagery. Remote Sens. Environ. 2012, 121, 370-388.

29. Campbell, G.S.; Norman, J.M. Introduction to Environmental Biophysics; Springer: New York, NY, USA, 1998.

30. Qin, J.; Yang, K.; Lu, N.; Chen, Y.; Zhao, L.; Han, M. Spatial upscaling of insitu soil moisture measurements based on MODIS-derived apparent thermal inertia. Remote Sens. Environ. 2013, 138, 1-9.

31. Chen, Y.; Yang, K.; Tang, W.; Qin, J.; Zhao, L. Parameterizing soil organic carbon's impacts on soil porosity and thermal parameters for eastern Tibet Grasslands. Sci. China Earth Sci. 2012, 55, 1001-1011.

32. Zhao, L.; Yang, K.; Qin, J.; Chen, Y.; Tang, W.; Montzka, C.; Wu, H.; Lin, C.; Han, M.; Vereecken, H. Spatiotemporal analysis of soil moisture observations within a Tibetan Mesoscale Area and its implication to regional soil moisture measurements. J. Hydrol. 2013, 482, 92-104.

33. NASA Data Center. Available online: http://reverb.echo.nasa.gov (accessed on 19 June 2015).

34. Liang, S.L. Narrowband to broadband conversions of land surface albedo I algorithms. Remote Sens. Environ. 2001, 76, 213-238.

35. Huete, A.; Didan, K.; Miura, T.; Rodriguez, E.P.; Gao, X.; Ferreira, L.G. Overview of the radiometric and biophysical performance of the MODIS vegetation indices. Remote Sens. Environ. 2002, 83, 195-213.

36. Donohue, R.J.; Roderick M.L.; McVicar T.R.; Farquar, G.D. Impact of $\mathrm{CO} 2$ fertilization on maximum foliage cover across the globe's warm, arid environments. Geophys. Res. Lett. 2013, 40, 3031-3035.

37. Choudhury, B.J.; Ahmed, N.U.; Idso, S.B.; Reginato, R.J.; Daughtry, C.S.T. Relations between evaporation coefficients and vegetation indices studied by model simulations. Remote Sens. Environ. 1994, 50, 1-17.

38. Zhou, X.; Guan, H.; Xie, H.; Wilson, J.L. Analysis and optimization of NDVI definitions and areal fraction models in remote sensing of vegetation. Int. J. Remote Sens. 2009, 30, 721-751.

39. China Meteorology Data Center. Available online: http://data.cma.gov.cn/ (accessed on 19 June 2015).

40. Shuttle Radar Topography Mission. Available online: http://srtm.csi.cginar.org/ (accessed on 19 June 2015).

41. Yang, K.; Qin, J.; Guo, X.; Zhou, D.; Ma, Y. Method development for estimating sensible heat flux over the Tibetan Plateau from CMA data. J. Appl. Meteorol. Climatol. 2009, 48, 2474-2486.

42. Haise, H.R.; Haas, H.J.; Jensen, L.R. Soil moisture studies of some great plains soils: II. Field capacity as related to $1 / 3$-atmosphere percentage, and "minimum point" as related to 15 - and 26-atmosphere percentages1. Soil Sci. Soc. Am. J. 1955, 19, 20-25.

43. Lei, Z.D.; Yang, S.X.; Xie, S.C. Soil Water Dynamics; Tsinghua University Press: Beijing, China, 1988. 
44. Schaap, M.G.; Leij, F.J.; van Genuchten, M.T. Neural network analysis for hierarchical prediction of soil hydraulic properties. Soil Sci. Soc. Am. J. 1998, 62, 847-855.

45. Ek, M.B.; Mitchell, K.E.; Lin, Y.; Rogers, E.; Grunmann, P.; Koren, V.; Gayno, G.; Tarpley, J.D. Implementation of noah land surface model advances in the national centers for environmental prediction operational mesoscale eta model. J. Geophys. Res.: Atmos. 2003, 108, 8851.

46. Koster, R.D.; Suarez, M.J. The components of a SVAT scheme and their effects on a GCMS hydrological cycle. Adv. Water Resour. 1994, 17, 61-78.

47. Liang, X.; Lettenmaier, D.P.; Wood, E.F.; Burges, S.J. A simple hydrologically based model of land surface water and energy fluxes for general circulation models. J. Geophys. Res.: Atmos. 1994, 99, 14415-14428.

48. Dai, Y.; Zeng, X.; Dickinson, R.E.; Baker, I.; Bonan, G.B.; Bosilovich, M.G.; Denning, A.S.; Dirmeyer, P.A.; Houser, P.R.; Niu, G.; et al. The common land model. Bull. Am. Meteorol. Soc. 2003, 84, 1013-1023.

49. Yang, Y.; Shang, S.; LI, C. Correcting the smoothing effect of ordinary kriging estimates in soil moisture interpolation. Adv. Water Sci. 2010, 21, 208-213.

50. Su, C.-H.; Ryu, D.; Young, R.I.; Western, A.W.; Wagner, W. Inter-comparison of microwave satellite soil moisture retrievals over the murrumbidgee basin, southeast australia. Remote Sens. Environ. 2013, 134, 1-11.

51. Chen, Y.; Yang, K.; Qin, J.; Zhao, L.; Tang, W.; Han, M. Evaluation of AMSR-E retrievals and GLDAS simulations against observations of a soil moisture network on the central Tibetan Plateau. J. Geophys. Res.: Atmos. 2013, 118, 4466-4475.

52. Long, D.; Scanlon, B.R.; Longuevergne, L.; Sun, A.Y.; Fernando, D.N.; Save, H. Grace satellite monitoring of large depletion in water storage in response to the 2011 drought in Texas. Geophys. Res. Lett. 2013, 40, 3395-3401.

53. Long, D.; Longuevergne, L.; Scanlon, B.R. Global analysis of approaches for deriving total water storage changes from grace satellites. Water Resour. Res. 2015, 51, 2574-2594.

54. Long, D.; Longuevergne, L.; Scanlon, B.R. Uncertainty in evapotranspiration from land surface modeling, remote sensing, and grace satellites. Water Resour. Res. 2014, 50, 1131-1151.

(C) 2015 by the authors; licensee MDPI, Basel, Switzerland. This article is an open access article distributed under the terms and conditions of the Creative Commons Attribution license (http://creativecommons.org/licenses/by/4.0/). 